\title{
Importance of the interaction between immune cells and tumor vasculature mediated by thalidomide in cancer treatment (Review)
}

\author{
XIN WANG $^{1,2}$, YANWEI SHEN ${ }^{1}$, SHUTING LI $^{1}$, MENG LV $^{1}$, XIAOMAN ZHANG ${ }^{1}$, \\ JIAO YANG $^{1}$, FAN WANG ${ }^{1}$ and JIN YANG $^{1}$ \\ ${ }^{1}$ Department of Medical Oncology, The First Affiliated Hospital of Xi'an Jiaotong University, Xi'an, Shaanxi 710061; \\ ${ }^{2}$ Department of Oncology, Shangluo Central Hospital, Shangluo, Shaanxi 726000, P.R. China
}

Received December 12,2015; Accepted August 25, 2016

DOI: $10.3892 /$ ijmm.2016.2724

\begin{abstract}
Over the past 60 years, thalidomide has metamorphosized from a drug prescribed to treat morning sickness in pregnant women, which was subsequently found to induce birth defects, into a highly effective therapy for treating leprosy and multiple myeloma. Several mechanisms have been proposed to explain the anticancer effects of thalidomide, including antiangiogenic and immunomodulatory activities. At present, evidence suggests that thalidomide may induce vessel maturation. Vascular normalization may be an effective strategy to enhance cancer immunotherapy. Numerous studies have shown that the tumor infiltrating immune cell subsets are important in regulating the process of tumor angiogenesis. The mechanisms associated with antiangiogenesis and the potent immunomodulatory effects of thalidomide obtained the most support. The studies of the antiangiogenic activity of thalidomide were guided in a novel direction by a hypothesis regarding the vascular normalization of tumors. Hence, thalidomide is effective in cancer treatment due to the interaction between immune cells and tumor vasculature. This mechanism provides new avenues to explore for the treatment of cancer.
\end{abstract}

\section{Contents}

1. Introduction

2. Mechanisms of action of thalidomide

3. Vascular normalization by thalidomide enhances immunomodulatory effect

4. Effect of thalidomide on angiogenesis and vascular remodeling mediated through various types of immune cells

5. Conclusion

Correspondence to: Professor Jin Yang, Department of Medical Oncology, The First Affiliated Hospital of Xi'an Jiaotong University, 227 Yanta West Road, Xi'an, Shaanxi 710061, P.R. China

E-mail: yangjin18991232383@126.com

Key words: thalidomide, vascular normalization, immune cells, cytokine, anticancer

\section{Introduction}

Thalidomide was initially synthesized as a non-addictive, non-barbiturate sedative by the German pharmaceutical company Chemie-Grünenthal in the late 1950's. It was discovered to be an effective antiemetic and was then used to control symptoms of nausea and vomiting in pregnant women. It was not until 1961 that thalidomide was validated as the cause of the largest man-made medical disaster in history with an estimated 10,000 children in 46 countries born with birth defects. Subsequently, thalidomide was withdrawn from most countries. In the following decades, the immunomodulatory and antiangiogenic effects of thalidomide were discovered and recognised as a novel indication for treatment with thalidomide. In 1965, Sheskin (1) serendipitously discovered that the immunomodulatory effects of thalidomide could be used to successfully cure erythema nodosum leprosum. In 1994, D'Amato et al (2) discovered that orally administered thalidomide inhibits angiogenesis induced by basic fibroblast growth factor (FGF) in a rabbit cornea micropocket assay. Due to these mechanisms, thalidomide was used to treat multiple myeloma and shown to be highly effective (3). To date, studies have been performed to examine the efficacy of thalidomide in the treatment of solid tumors, such as prostate cancer, glioblastoma and squamous cell carcinoma of the neck (4-8).

In 2005, Jain suggested that certain antiangiogenic agents can also 'normalize' the abnormal structure and function of tumor vasculature to make it more efficient for oxygen and drug delivery (9). Subsequently, several studies of thalidomide suggested that it reduces tumor vessel density and tumor interstitial fluid pressure, while improving perfusion and oxygenation in preclinical fibrosarcoma and liver carcinoma models. Although the time of improved oxygenation only lasted for 2-4 days of thalidomide treatment (10), it demonstrated that thalidomide probably temporarily reversed tumor vessels towards a more normal phenotype. In vitro, thalidomide analogs also inhibited proliferative effects on human umbilical vein endothelial cells (11). These studies explored the vascular remodeling effect of thalidomide without associating vascular normalization with effects on immune cells. The immunomodulatory properties of thalidomide have been the focus of mechanistic studies of the therapeutic effects of thalidomide in patients with different types of cancer (12-14). The potent 
immunomodulatory activity of thalidomide mainly alters the secretion and activity of various cytokines (12-18). To some extent, these cytokines control the balance between proangiogenic and anti-angiogenic effects. Thalidomide has also been demonstrated to regulate immune cells, such as regulatory $\mathrm{T}$ cells (Treg) and natural killer (NK) cells, which resulted in enhanced tumor surveillance defence (13). The potential 'vascular normalization' of thalidomide may also create a microenvironment of immune-activating cells in tumors, thereby leading to immune cell polarization and cytokine changes. Thus, we suggest that the interaction between immune cells and normal tumor vasculature is the principal mechanism responsible for the effects of thalidomide in the treatment of cancer.

In this review, we have discussed the regulation of the interplay between tumor vessels and immune cells by thalidomide. Targeted therapy with thalidomide may improve the efficacy of anticancer therapy.

\section{Mechanisms of action of thalidomide}

Antiangiogenic activity of thalidomide. The mechanism responsible for the antiangiogenic effects of thalidomide has been discovered and defined. D'Amato et al have determined the critical role of angiogenesis in the progression and metastasis of cancer, based on antiangiogenic effects in rabbits, and thalidomide was first examined as a novel agent for the treatment of patients with resistant myeloma $(2,3)$. Subsequently, the potential antiangiogenic effects of thalidomide were also demonstrated in humans and several other species (19-22). Many clinical and preclinical investigations showed that the antiangiogenic activity of thalidomide is associated with a series of events as well as certain molecules. Verheul et al (23) demonstrated that thalidomide is capable of inhibiting the effects of FGF2 or vascular endothelial growth factor (VEGF) on tumor growth in an animal model. The decreased plasma levels of angiogenic growth factors in patients with multiple myeloma treated with thalidomide were documented by Bertolini et al (24). Such effects were also observed in other types of cancer, such as lung adenocarcinoma as well as head and neck squamous cell carcinoma $(25,26)$. Furthermore, the effects of insulin-like growth factor (IGF)-1 and FGF2 can be reversed by thalidomide. Thalidomide eliminates their stimulation of the transcription of $\alpha \mathrm{v}$ and $\beta 3$ integrin subunit genes through intercalating into the GC box in the promoters of IGF-1 and FGF2 genes, which inhibits the angiogenic effects of the $\alpha v \beta 3$ integrin dimer $(27,28)$. It has also been noted that thalidomide is involved in the inhibition of cyclooxygenase-2 (COX-2), a key enzyme responsible for the formation of prostaglandins (PGs) (29). COX-2 was shown to be required for angiogenesis in a rat corneal model and COX-2-derived PGE2, which is a potent inducer of the angiogenic switch during the progression of mammary cancer $(30,31)$. Many important molecules involved in embryonic vascular development and patterning have been reported to exhibit changed expression patterns following thalidomide exposure, for example, actin, tubulin, integrins, VEGF, platelet-derived growth factor (PDGF) $\beta$, nitric oxide, ceramide, angiopoietins (Ang), Notch, hypoxia-inducible factor (HIF), Slit2/Robo signaling and reactive oxygen species $(27,28,32-35)$. These molecules are associated with angiogenesis in both physiological and pathological states, and thalidomide can inhibit angiogenesis through affecting changes in the expression of these molecules. However, it remains unclear whether the mechanism of thalidomide regulation can exert different effects on tumor angiogenesis.

Normalization of tumor vasculature by thalidomide. It is now well established that angiogenesis plays a major role in the aggressive behavior and metastatic potential of various solid tumors. However, the antitumor effects of thalidomide did not always correlate with reductions in tumor microvessels in patients. Despite observing a strong association between thalidomide and decreased microvessel density in xenografted primary human myeloma cells in a mouse model which responded to treatment, it was not possible to conclude whether reduced microvessel density is a primary result of the anti-angiogenic activity of thalidomide or secondary to reduced tumor burden (2). Patients or the animal model treated with thalidomide appeared to exhibit survival benefits due to the alleviation of hypoxia and the increased perfusion/oxygenation as well as the reduced microvessel density of the tumor (3). Thus, thalidomide was discovered to induce tumor reoxygenation and extensive vascular remodeling when combined with radiotherapy and chemotherapy $(10,36)$. These findings suggest that thalidomide is capable of remodeling tumor vessels and promoting the normalization of tumor vasculature. Therefore, the mechanisms addressing the anti-angiogenic activity of thalidomide are complex and yet to be completely elucidated. In addition, it was discovered that thalidomide and its analogs can decrease levels of pro-angiogenic factors and increase antiangiogenic factors in vivo and in vitro. Lebrin et al analyzed whether the target vessel effect of thalidomide in individuals with hereditary hemorrhagic telangiectasia (HHT) correlated with PDGF-B (37). Thalidomide treatment stimulated mural cell coverage and rescued vessel wall defects. It also increased PDGF-B expression in endothelial cells and stimulated mural cell activation. Moreover, simultaneous treatment of postnatal wild-type mice with a high dose of thalidomide and imatinib mesylate, a potent inhibitor of PDGF receptor tyrosine kinase activity, was sufficient to restore postnatal retinal vascular development. Thus, blocking PDGF signaling counteracts the effects of thalidomide on angiogenesis and on the apposition of pericytes to the endothelial cells of the blood vessels. Therefore, the data has established PDGF as a key mediator of the effects of thalidomide. This study established the association between thalidomide and vascular normalization in HHT. At the same time, the investigator discovered that vascular normalization is dependent on the dose of thalidomide. High doses of thalidomide $\left(100 \mu \mathrm{g} \mathrm{ml}^{-1}\right)$ caused vessel pruning and inhibited vessel formation. By contrast, lower doses $\left(10-50 \mu \mathrm{g} \mathrm{ml}^{-1}\right)$ enhanced endothelial sprouting, and low concentrations $\left(25 \mu \mathrm{g} \mathrm{ml}^{-1}\right)$ stimulated the recruitment of mural cells to the vessel branches (37). Clinical manifestations of HHT include arteriovenous malformations, which resemble the morphology of heterogeneous tumor vessels. The data demonstrated the ability of thalidomide to induce vessel maturation, which could be a potential indication for the study of thalidomide in cancer treatment. The vascular normalization hypothesis proposes that direct or indirect antiangiogenic therapy usually restores the imbalance between pro- and 
anti-angiogenic factors back towards equilibrium. As a result, vessel structure and function become normal (38).

Immunomodulatory properties of thalidomide. Cytokines are inflammatory mediators that play important roles in the pathogenesis of cancer. Over the last few decades, efforts have focused on ways to use cytokines to manipulate the host immune response towards recognising and eradicating cancer cells (39). Thalidomide regulates the secretion and activity of various cytokines including interleukin (IL), tumor necrosis factor (TNF), interferon (IFN) and growth factor. These modulatory effects of thalidomide may contribute to the suppression of proliferation, inflammation and angiogenesis as well as of the immune system. Thalidomide can inhibit the effects of FGF2 or VEGF resulting in anti-angiogenic effects on tumor growth in animal model (28). As a pro-inflammatory cytokine, TNF- $\alpha$ plays a critical role in cancer. Thalidomide inhibited TNF- $\alpha$ synthesis by increasing the degradation of TNF- $\alpha$ mRNA which resulted in the decreased expression of multiple cell surface adhesion molecules. These broad effects have been attributed to the blocking of the activation of nuclear factor- $\kappa \mathrm{B}(\mathrm{NF}-\kappa \mathrm{B})$ which is a key transcriptional regulator of inflammatory genes. Thalidomide achieved the modulations by suppressing $\mathrm{I} \kappa \mathrm{B}$ kinase activity and contributing to the suppression of the proliferation of cancer cells. On the one hand, thalidomide acts to costimulate $\mathrm{CD} 8^{+} \mathrm{T}$ cells resulting in the enhanced production of IL-2, IL-12 and IFN- $\alpha$ (17). On the other hand, IL-2 in turn enhances T cell proliferation whereas IL-12 and IFN- $\alpha$ activate NK cells to eliminate cancer cells $(12,13)$. Thus, thalidomide significantly enhances antiangiogenic and antitumor activities by regulating changes in cytokine expression in the tumor milieu. Moreover, thalidomide also increases the susceptibility of cancer cells to apoptosis by downregulating the antiapoptotic protein $\mathrm{Bcl}-2$ and enhancing the sensitivity to Fas-induced apoptosis, and downregulating NF- $\kappa \mathrm{B}$ activity $(40,41)$. In addition to immunomodulatory properties, thalidomide is associated with DNA damage and oxidative stress through a signaling pathway mediating different cytokines. In 2010, thalidomide was found to bind to the protein cereblon (21) which led to the activation of immune cells and the secretion of cytokines. Thus, another novel signaling pathway between cytokines and immune cells via the downstream targets of the complex with thalidomide was established. While low amounts of cereblon in multiple myeloma cells correlate with clinical drug resistance and poor survival outcomes (42), this novel mechanism of thalidomide may lead to the identification of a new class of therapeutics for treatment of another type of cancer.

\section{Vascular normalization by thalidomide enhances immunomodulatory effect}

Since the vascular changes alone are unlikely to explain the inhibition of tumor growth by thalidomide, the immune response of tumors through vascular normalization is probably involved. The vascular system ensures the delivery of immune cells to all organs and tissues (43). Therefore abnormal tumor vasculature creates a hypoxic microenvironment that polarizes immune cells toward immune suppression. Simultaneously, hypoxia alters various metabolic pathways in cancer cells leading to the accu- mulation of immunosuppressive metabolites $(44,45)$. Hence, treatments resulting in vascular normalization may be an effective modality to potentiate immunomodulatory effects (46). Thalidomide, an agent possessing the potential function of vascular normalization, stimulates vessel maturation and alleviates hypoxia, so the normalization of the tumor microenvironment by repairing the function of tumor vessels may be a promising strategy to enhance immunomodulatory effects and slow tumor progression. RGS5 deficiency and the histidinerich glycoprotein (HRG) have been demonstrated to show a mechanistic link between vessel normalization and enhancing immune cell infiltration and function $(47,48)$. Many studies have demonstrated the benefits of antiangiogenic treatment on the efficacy of cancer immunotherapy in terms of pharmacological and clinical implications (Table I). These results suggest that there is a strong correlation between immune cells and vascular normalization, as shown in Fig. 1. This may represent a potential mechanism of thalidomide.

Thalidomide was demonstrated to transiently 'normalize' the abnormal structure and function of tumor vasculature in order to enhance the efficiency of oxygen and drug delivery (20). It has also been shown to possess potent anti-inflammatory and immunomodulatory activities. Tumor-related angiogenesis supports tumor growth and is also a main obstacle for successful immune therapy as it prevents the migration of immune effector cells into established tumor parenchyma. Thalidomide potentially remodeled tumor vessels and then attracted immune effector cells into the established tumor parenchyma. Thalidomide probably polarizes the immune cell phenotype and forms an immunosupportive tumor microenvironment by vascular normalization resulting in the inhibition of tumor growth. The molecular mechanisms responsible for the effects of thalidomide on immune cells and vascular normalization will be the focus of future studies as therapeutic effects in patients with different types of cancer were associated with both properties.

\section{Effect of thalidomide on angiogenesis and vascular remodeling mediated through various types of immune cells}

Thalidomide affects immune cells. In clinical investigations, the type and density of intra-tumoral immune cells were validated as reliable parameters for the evaluation of patient clinical outcomes in certain types of cancer (49-51). Therapies targeting immune cells has been an efficient strategy for treating tumors. Although the immunomodulatory activity of thalidomide mainly lies in its capability to alter the secretion and activity of various cytokines, thalidomide has been extensively investigated for $\mathrm{T}$ cell costimulation and modulation of the activities of NK cells. Thalidomide suppressed tumor growth by activating $\mathrm{T}$ cells in HIV-infected individuals and NK cells in mice $(13,17)$. Lenalidomide and pomalidomide, which are thalidomide analogues, strongly inhibit the proliferation of Tregs as well as suppressing the function of Tregs. This outcome suggests that thalidomide may potentially inhibit Tregs, which may help to overcome an important barrier to tumor-specific immunity in cancer patients (52).

An efficient immune response depends on the appropriate distribution and positioning of immune cells within dynamic tissue microenvironments. The different immune cells can 
Table I. Benefits of combined antiangiogenic and active immune therapies.

\begin{tabular}{|c|c|c|c|}
\hline Antiangiogenic strategy & Immunotherapy & Tumor model & Results \\
\hline Anti-mouse VEGF mAb & Peptide-pulsed DCs & Sarcoma & $\begin{array}{l}\text { Increased number and function of DCs; } \\
\text { Increased tumor growth delay }\end{array}$ \\
\hline Anti-VEGF2 mAb & $\begin{array}{l}\text { GM-CSF secreting, } \\
\text { neu-specific whole } \\
\text { tumor cell vaccine }\end{array}$ & $\begin{array}{l}\text { Neu-expressing } \\
\text { breast carcinoma }\end{array}$ & $\begin{array}{l}\text { Increased infiltration of } \mathrm{CD}^{+} \mathrm{T} \text { cells; } \\
\text { Increased tumor regression (in FVB } \\
\text { mice, but not neu-N/FVB mice) }\end{array}$ \\
\hline Anti-mouse VEGF mAb & PVI & Melanoma & $\begin{array}{l}\text { Increased immune cell infiltration; } \\
\text { Increased tumor growth delay }\end{array}$ \\
\hline Rgs5 knockout & $\mathrm{ACT}$ & $\begin{array}{l}\text { Insulinoma, } \\
\text { fibrosarcoma }\end{array}$ & $\begin{array}{l}\text { Increased immune cell infiltration; } \\
\text { Increased survival }\end{array}$ \\
\hline $\begin{array}{l}\text { Low dose anti-VEGFR2 } \\
\mathrm{mAb}\end{array}$ & $\begin{array}{l}\text { Mitomycin-C treated } \\
\text { whole breast tumor } \\
\text { cell vaccine }\end{array}$ & Breast carcinoma & $\begin{array}{l}\text { Increased infiltration of } \mathrm{CD}^{+} \text {and } \mathrm{CD}^{+} \\
\mathrm{T} \text { cells; } \\
\text { Decreased MDSCs and Tregs; } \\
\text { Increased survival }\end{array}$ \\
\hline $\begin{array}{l}\text { Adenoviral delivery of } \\
\text { sVEGFR1/R2 }\end{array}$ & $\begin{array}{l}\text { GM-CSF-secreting } \\
\text { whole tumor cell } \\
\text { vaccine }\end{array}$ & $\begin{array}{l}\text { Melanoma, } \\
\text { colon carcinoma }\end{array}$ & $\begin{array}{l}\text { Increased number of activated } \mathrm{CD}^{+} \\
\text {and } \mathrm{CD} 8^{+} \mathrm{T} \text { cells; } \\
\text { Decreased Treg; } \\
\text { Increased survival }\end{array}$ \\
\hline SU6668 & $\begin{array}{l}\text { Recombinant murine } \\
\text { B7.2-IgG fusion protein } \\
\text { and irradiated whole } \\
\text { tumor cell vaccine }\end{array}$ & Breast carcinoma & $\begin{array}{l}\text { Increased infiltration of } \mathrm{CD}^{+} \mathrm{T} \text { cells; } \\
\text { Increased tumor growth delay }(34)\end{array}$ \\
\hline Sunitinib & $\begin{array}{l}\text { Intratumoral IL-12 } \\
\text { gene delivery by } \\
\text { adenoviral vector } \\
\text { plus 4-1BB activation }\end{array}$ & Colon carcinoma & $\begin{array}{l}\text { Increased infiltration of } \mathrm{CD}^{+} \text {and } \mathrm{CD}^{+} \\
\mathrm{T} \text { cells; } \\
\text { Decreased MDSCs and Tregs; } \\
\text { Increased survival }\end{array}$ \\
\hline Sunitinib & & RCC patients & $\begin{array}{l}\text { Decreased MDSCs and Tregs; } \\
\text { Increased type } 1 \text { T cell activity; }\end{array}$ \\
\hline Low dose TNF- $\alpha$ & Adoptive T cell transfer & Insulinoma & $\begin{array}{l}\text { Increased infiltration of } \mathrm{CD}^{+} \mathrm{T} \text { cells; } \\
\text { Increased survival }\end{array}$ \\
\hline
\end{tabular}

mAb, monoclonal antibody; DC, dendritic cell; MDSC, myeloid-derived suppressor cell; VEGF, vascular endothelial growth factor; VEGFR2, VEGF receptor 2; GM-CSF, granulocyte-macrophage colony-stimulating factor; PVI, the administration of anti-GP100 transgenic pmel-1 T cells plus GP100 vaccine plus IL-2 injection after 500cGy lymphodepleting whole body irradiation; ACT, adoptive cell transfer; RCC, renal cell carcinoma; IL, interleukin. SU6668 is an inhibitor of tyrosine kinase activity of the angiogenic receptors VEGFR2, PDGFR $\beta$, and FGFR1; sunitinib is an inhibitor of tyrosine kinase activity of VEGFR2 and PDGFR (46).

also affect blood vessel neoformation and remodeling (53-55). As summarized in Fig. 2, every type of immune cell has been shown to affect the process of tumor angiogenesis either directly or indirectly by releasing regulatory cytokines. Thalidomide may probably affect angiogenesis and vascular remolding by affecting immune cells.

\section{Immune cells affect angiogenesis and vascular remolding}

Macrophages. General immune cells exert functions through the release of cytokines. In solid tumors, macrophages are often attracted to the hypoxic areas of tumor sites due to the secretion of hypoxia-induced chemoattractants by tumor cells. Such chemoattractants include different cytokines such as VEGF, endothelin, endothelial monocyte-activating polypeptide II (EMAP II) (56) and CCL2 (57). Subsequently, tumor-associated macrophages (TAMs) are recruited to the hypoxic areas. This microenvironment promotes the metabolic adaptation of TAMs to hypoxia by upregulating HIF-1, HIF-2 and VEGF (58-60). Macrophages are attracted to the hypoxic areas of tumor site, which produce a large amount of pro-angiogenic factors, in addition to angiogenesis-modulating enzymes under the regulation of specific signaling pathways (i.e., NF- $\kappa \mathrm{B}$ and $\mathrm{mTOR}$ ) and transcription factors (i.e., HIFs and Stat3), which contribute to tumor angiogenesis. These molecules can switch angiogenesis or remold tumor vessels, resulting in the alleviation of hypoxia and increased tumor perfusion/oxygenation. A study determined the effects of thalidomide in the pathogenesis of asthmatic airways using a mouse model of allergic asthma as well as the underlying mechanism responsible for these effects. When the ovalbumin-sensitized mice were treated with thalidomide, the mRNA expression of RELM- $\alpha$, Arg-1, CD206 


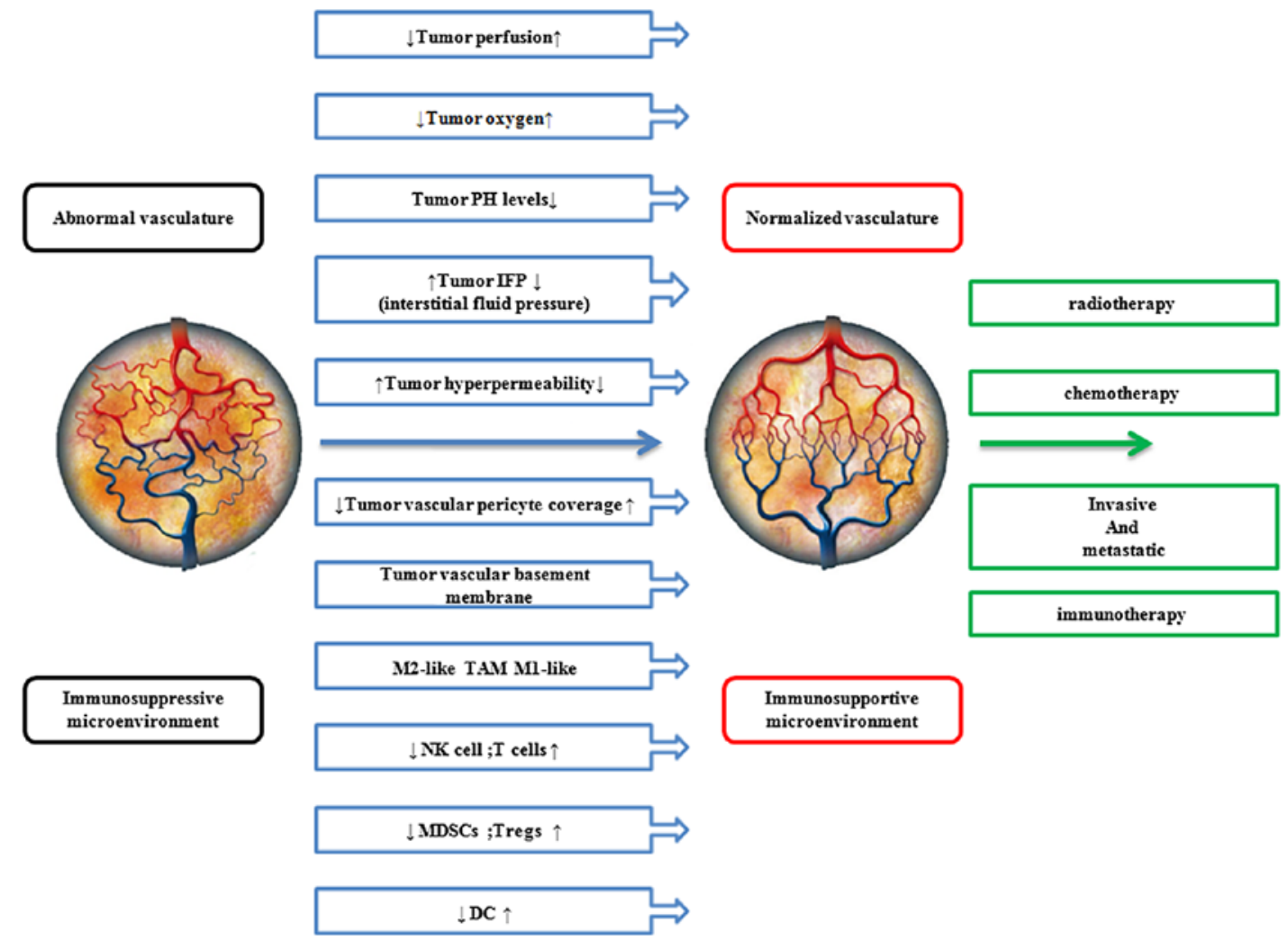

Figure 1. The structural abnormalities of the tumor vasculature impede immune cell infiltration into tumors and create a hypoxic and acidic tumor microenvironment that upregulates dendritic cells; increases the accumulation of regulatory T cells (Tregs) and polarizes tumor-associated macrophages (TAMs) to the immune inhibitory M2-like phenotype. Vascular normalization is characterized by the attenuation of hyperpermeability, increased vascular pericyte coverage, a more normal basement membrane, and a resultant reduction in tumor hypoxia and interstitial fluid, facilitating the infiltration of immune cells while reducing the accumulation of myeloid-derived suppressor cells (MDSCs) and Tregs. In addition, alleviating hypoxia and acidity by improving vascular perfusion polarizes TAMs to an immunostimulatory M1-like phenotype. Adapted and updated from Goel et al, Rolny et al and Jain $(38,48,73)$.

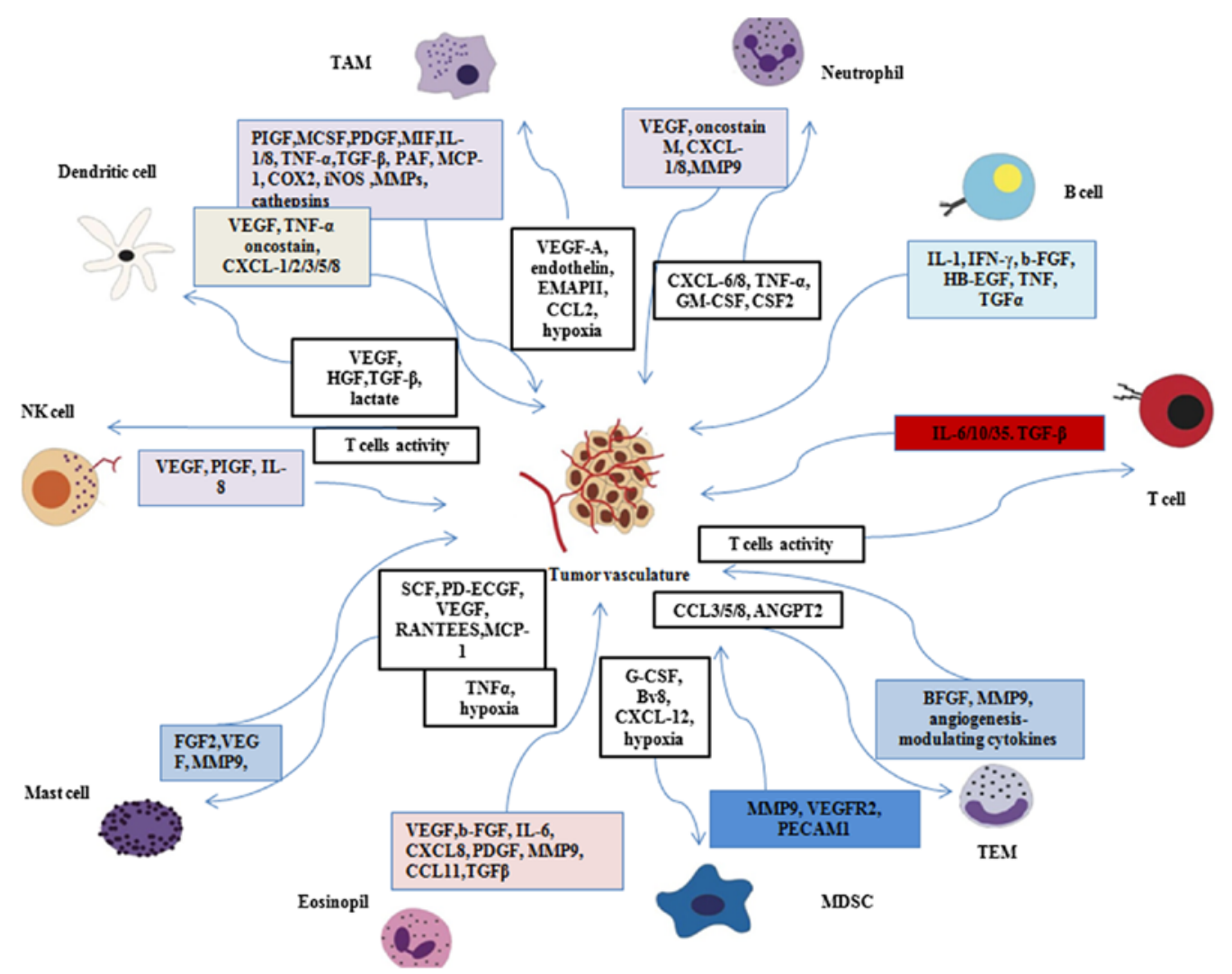

Figure 2. Reciprocal interactions between different immune cell types and the tumor vasculature in the tumor microenvironment (72). 


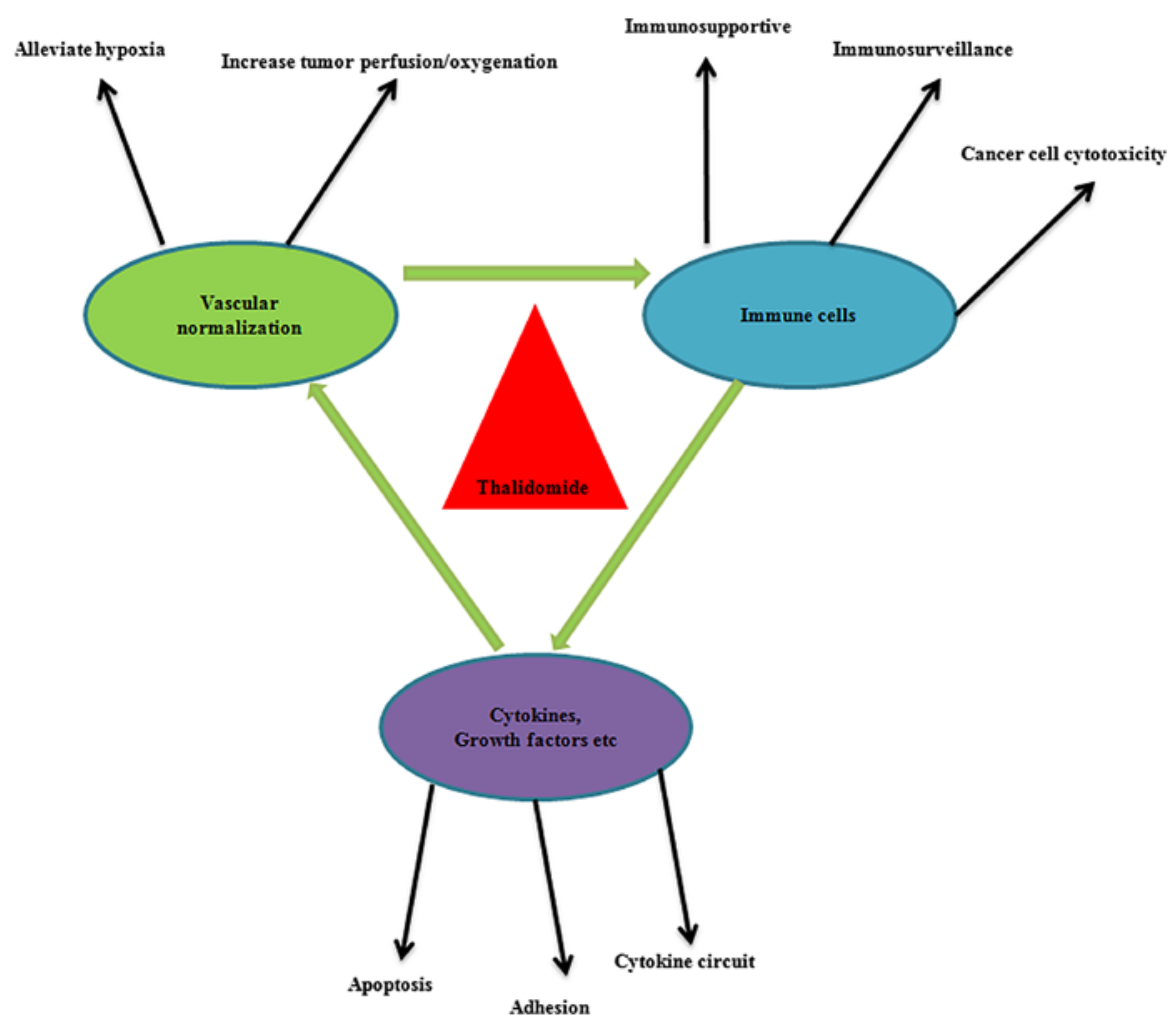

Figure 3. Thalidomide exerts anticancer effects through vascular normalization, modulation of immune cell activities and the release of cytokines. Interactions exist between the different mechanisms.

and YM-1 in the lungs was significantly reduced. Thalidomide inhibited the expression of M2 macrophages (protumoral and pro-angiogenic TAMs) in vivo and in vitro (61). Rolny et al (48) treated tumor-bearing (T241 fibrosarcoma and Panc02 tumor) mice with clodronate liposomes to chemically deplete TAMs, which suggested that M2-like TAMs induced vessel normalization. This study further identified an inhibitory effect of thalidomide on alternative activation of macrophages as a potential antitumor mechanism. Furthermore, thalidomide probably mediates tumor vessel normalization through the alternative activation of macrophages.

$N K$ cells and T cells. NK cells are cells of the innate immune system that arise from a common lymphoid progenitor cell. These cells are characterized by a high cytolytic capacity against cancer cells. In addition to their important role in immunosurveillance, NK cells contribute to neovascularization. The expression of IFN inducible protein (IP)-10, IFN- $\alpha$, IL-12 and IL-18 was markedly upregulated following the administration of thalidomide in order to modulate NK cell activity in a murine model of melanoma (13). The upregulated cytokines are associated with angiogenesis. The CD56(+) CD16(-) NK subset [decidual NK (dNK) cells] in non-small cell lung cancer patients was associated with VEGF, placental growth factor (PIGF), and IL-8/CXCL8 production. This suggests that thalidomide probably affects vessel remolding by regulating the secretion of pro-angiogenic cytokines by NK cells (62). However, the precise role of thalidomide and NK cells in tumor vascular normalization remains to be defined. More studies have suggested that thalidomide may also act as an inducer of $\mathrm{T}$ cell stimulatory signals, inducing $\mathrm{T}$ cell proliferation in association with IFN- $\alpha$ and IL-2 production $(15,63)$. T cells can directly regulate the level of MHC expression through IFN- $\gamma$ secretion $(64,65)$, but also improve the regulatory functions of endothelial cells (ECs), namely, the regulation of blood vessel formation and remodeling, blood flow, permselectivity, blood fluidity and hemostasis (66). T cells not only affect the cytoskeletal rearrangement in ECs and thrombi but are also implicated in the regulation of the inhibitory molecule programmed cell death-1 ligand (PD-L1) by T cell-derived cytokines. Thus, thalidomide modulated immune cells to improve vascular normalization through the production of cytokines.

Immune cells affect angiogenesis and vascular remolding through cytokines. Angiogenesis was demonstrated to be important in supporting tumor growth, whereas infiltrating cancer cells contributed to the tumor microenvironment through the secretion ofgrowth factors, cytokines and important molecules in the cancer cells (67). Similarly, cytokines were crucial in the development of tumors, the activation of the immune response and angiogenesis in cancer. Thalidomide directly altered the expression of cytokines but also regulated the secretion of cytokines from immune cells indirectly. Through the two pathways, thalidomide achieved antiangiogenesis and vascular normalization in cancer. As modulators of tumor angiogenesis, cytokines have been therapeutic targets in angiogenesis (68).

TAMs are capable of releasing a number of cytokines (such as IL-1, IL-8 or TNF- $\alpha$ ), which was the novel pivotal factor of TAMs in facilitating tumor angiogenesis $(69,70)$. Various mouse models have shown that neutrophils are crucially involved in the process of tumor angiogenesis. The depletion of neutrophils impaired angiogenesis in mice inoculated with 
CXCL8 as well as in a transgenic RIPK1-Tag2 mouse model of pancreatic carcinoma (72). Mast cells driving neo-angiogenesis have been documented to express Ang-1 (71). Tumor-associated dendritic cells (DCs) can directly drive tumor angiogenesis through the release of pro-angiogenic cytokines such as TNF- $\alpha$, CXCL8 and osteopontin (71). The above-mentioned studies suggest that a complex relationship exists between immune cells, tumor vessels and cytokines. Cytokines probably link vascular normalization with immune cells. As thalidomide is capable of altering the secretion and activity of various cytokines and inducing an immune response, it may affect the interactions between immune cells and the tumor vasculature through these cytokines.

\section{Conclusion}

Over the last few decades, thalidomide has undergone a remarkable metamorphosis from a notorious drug inducing birth defects into a highly effective therapy for treating leprosy and multiple myeloma. Today, thalidomide is used to treat a wide range of medical conditions successfully, which include cancer.

The mechanisms associated with antiangiogenesis and the potent immunomodulatory effects of thalidomide obtained the most support. Subsequently, the studies of the antiangiogenic activity of thalidomide were guided into a novel direction by a hypothesis regarding the vascular normalization of tumors. As summarized in Fig. 3, the potential normalization of tumor vessels by thalidomide may be an effective strategy for reconditioning the tumor immune microenvironment in order to produce anticancer effects. On the other hand, it is recognized that the immune cell compartment within the tumor is a major driver of angiogenesis and vascular remodeling (72). Angiogenic activity within a tumor is affected by many different types of immune cell which release cytokines and angiogenic factors. Tumors are highly heterogeneous. Despite the multiple mechanisms of action responsible for the therapeutic effects of thalidomide discussed previously, the precise mode of action of thalidomide remains to be completely elucidated. Further studies are warranted in order to clarify whether thalidomide needs to target different pro-angiogenic factors to induce vascular normalization in different tumors, at different times, as well as on interconnections between the immune cells and tumor vasculature and thereby elucidate the therapeutic effects of thalidomide in cancer. Future studies regarding the association between the effects of immune cells and vascular normalization action modes are also of paramount significance. These studies may enable thalidomide to be used in more effective ways.

\section{References}

1. Sheskin J: Thalidomide in the treatment of lepra reactions. Clin Pharmacol Ther 6: 303-306, 1965.

2. D'Amato RJ,Loughnan MS, Flynn E and Folkman J: Thalidomide is an inhibitor of angiogenesis. Proc Natl Acad Sci USA 91: 4082-4085, 1994.

3. Singhal S, Mehta J, Desikan R, Ayers D, Roberson P, Eddlemon P, Munshi N, Anaissie E, Wilson C, Dhodapkar M, et al: Antitumor activity of thalidomide in refractory multiple myeloma. N Engl J Med 341: 1565-1571, 1999.

4. Drake MJ, Robson W, Mehta P, Schofield I, Neal DE and Leung HY: An open-label phase II study of low-dose thalidomide in androgenindependent prostate cancer. Br J Cancer 88: 822-827, 2003.
5. Marx GM, Pavlakis N, McCowatt S, Boyle FM, Levi JA, Bell DR, Cook R, Biggs M, Little N and Wheeler HR: Phase II study of thalidomide in the treatment of recurrent glioblastoma multiforme. J Neurooncol 54: 31-38, 2001.

6. Figg WD, Dahut W, Duray P, Hamilton M, Tompkins A, Steinberg SM, Jones E, Premkumar A, Linehan WM, Floeter MK, et al: A randomized phase II trial of thalidomide, an angiogenesis inhibitor, in patients with androgen-independent prostate cancer. Clin Cancer Res 7: 1888-1893, 2001.

7. Eleutherakis-Papaiakovou V, Bamias A and Dimopoulos MA: Thalidomide in cancer medicine. Ann Oncol 8: 1151-1160, 2004.

8. Kesari S, Schiff D, Henson JW, Muzikansky A, Gigas DC Doherty L, Batchelor TT, Longtine JA, Ligon KL, Weaver S, et al: Phase II study of temozolomide, thalidomide, and celecoxib for newly diagnosed glioblastoma in adults. Neuro Oncol 10: 300-308, 2008 .

9. Jain RK: Normalization of tumor vasculature: an emerging concept in antiangiogenic therapy. Science 307: 58-62, 2005.

10. Ansiaux R, Baudelet C, Jordan BF, Beghein N, Sonveaux P, De Wever J, Martinive P, Grégoire V, Feron O and Gallez B: Thalidomide radiosensitizes tumors through early changes in the tumor microenvironment. Clin Cancer Res 11: 743-750, 2005.

11. El-Aarag BY, Kasai T, Zahran MA, Zakhary NI, Shigehiro T, Sekhar SC, Agwa HS, Mizutani A, Murakami H, Kakuta H and Seno M: In vitro anti-proliferative and anti-angiogenic activities of thalidomide dithiocarbamate analogs. Int Immunopharmacol 21: 283-292, 2014.

12. Davies FE, Raje N, Hideshima T, Lentzsch S, Young G, Tai YT, Lin B, Podar K, Gupta D, Chauhan D, et al: Thalidomide and immunomodulatory derivatives augment natural killer cell cytotoxicity in multiple myeloma. Blood 98: 210-216, 2001.

13. Kawamata A, Ito D, Odani T, Isobe T, Iwase M, Hatori M and Nagumo M: Thalidomide suppresses melanoma growth by activating natural killer cells in mice. Oncol Rep 16: 1231-1236, 2006.

14. von Moos R, Stolz R, Cerny T and Gillessen S: Thalidomide: from tragedy to promise. Swiss Med Wkly 133: 77-87, 2003.

15. Corral LG, Haslett PA, Muller GW, Chen R, Wong LM, Ocampo CJ, Patterson RT, Stirling DI and Kaplan G: Differential cytokine modulation and $\mathrm{T}$ cell activation by two distinct classes of thalidomide analogues that are potent inhibitors of TNF-alpha. J Immunol 163: 380-386, 1999.

16. Corral LG and Kaplan G: Immunomodulation by thalidomide and thalidomide analogues. Ann Rheum Dis 58 (Suppl 1): I107-I113, 1999.

17. Haslett PA, Klausner JD, Makonkawkeyoon S, Moreira A, Metatratip P, Boyle B, Kunachiwa W, Maneekarn N, Vongchan P, Corral LG, et al: Thalidomide stimulates $\mathrm{T}$ cell responses and interleukin 12 production in HIV-infected patients. AIDS Res Hum Retroviruses 15: 1169-1179, 1999.

18. Muller GW, Chen R, Huang SY, Corral LG, Wong LM, PattersonRT,Chen Y,Kaplan G and Stirling DI:Amino-substituted thalidomide analogs: potent inhibitors of TNF-alpha production. Bioorg Med Chem Lett 9: 1625-1630, 1999.

19. Joussen AM, Germann T and Kirchhof B: Effect of thalidomide and structurally related compounds on corneal angiogenesis is comparable to their teratological potency. Graefes Arch Clin Exp Ophthalmol 237: 952-961, 1999.

20. Therapontos C, Erskine L, Gardner ER, Figg WD and Vargesson N: Thalidomide induces limb defects by preventing angiogenic outgrowth during early limb formation. Proc Natl Acad Sci USA 106: 8573-8578, 2009.

21. Ito T, Ando H, Suzuki T, Ogura T, Hotta K, Imamura Y, Yamaguchi $Y$ and Handa $H$ : Identification of a primary target of thalidomide teratogenicity. Science 327: 1345-1350, 2010.

22. Yabu T, Tomimoto H, Taguchi Y, Yamaoka S, Igarashi Y and Okazaki T: Thalidomide-induced antiangiogenic action is mediated by ceramide through depletion of VEGF receptors, and is antagonized by sphingosine-1-phosphate. Blood 106: 125-134, 2005.

23. Verheul HM, Panigrahy D, Yuan J and D'Amato RJ: Combination oral antiangiogenic therapy with thalidomide and sulindac inhibits tumour growth in rabbits. Br J Cancer 79: 114-118, 1999.

24. Bertolini F, Mingrone W, Alietti A, Ferrucci PF, Cocorocchio E, Peccatori F, Cinieri S, Mancuso P, Corsini C, et al: Thalidomide in multiple myeloma, myelodysplastic syndromes and histiocytosis. Analysis of clinical results and of surrogate angiogenesis markers. Ann Oncol 12: 987-990, 2001. 
25. Li X, Liu X, Wang J, Wang Z, Jiang W, Reed E, Zhang Y, Liu Y and Li QQ: Effects of thalidomide on the expression of angiogenesis growth factors in human A549 lung adenocarcinoma cells. Int J Mol Med 11: 785-790, 2003.

26. Vasvari GP, Dyckhoff G, Kashfi F, Lemke B, Lohr J, Helmke BM, Schirrmacher V, Plinkert PK, Beckhove P and Herold-Mende CC: Combination of thalidomide and cisplatin in an head and neck squamous cell carcinomas model results in an enhanced antiangiogenic activity in vitro and in vivo. Int J Cancer 121: 1697-1704, 2007.

27. Stephens TD, Bunde CJ and Fillmore BJ: Mechanism of action in thalidomide teratogenesis. Biochem Pharmacol 59: 1489-1499, 2000.

28. Stephens TD and Fillmore BJ: Hypothesis: thalidomide embryopathy-proposed mechanism of action. Teratology 61: 189-195, 2000.

29. Fujita J, Mestre JR, Zeldis JB, Subbaramaiah K and Dannenberg AJ: Thalidomide and its analogues inhibit lipopolysaccharide-mediated linduction of cyclooxygenase-2. Clin Cancer Res 7: 3349-3355, 2001.

30. Chang SH, Liu CH, Conway R, Han DK, Nithipatikom K, Trifan OC, Lane TF and Hla T: Role of prostaglandin E2-dependent angiogenic switch in cyclooxygenase 2-induced breast cancer progression. Proc Natl Acad Sci USA 101: 591-596, 2004.

31. Yamada M, Kawai M, Kawai Y and Mashima Y: The effect of selective cyclooxygenase-2 inhibitor on corneal angiogenesis in the rat. Curr Eye Res 19: 300-304, 1999.

32. Vargesson $\mathrm{N}$ : Thalidomide-induced limb defects: resolving a 50-year-old puzzle. BioEssays 31: 1327-1336, 2009.

33. Vargesson N: Thalidomide embryopathy: An enigmatic challenge. ISRN Dev Biol: 241016, 2013. doi.org/10.1155/2013/241016.

34. Feng Q, Tan HH, Ge ZZ, Gao YJ, Chen HM and Xiao SD Thalidomide-induced angiopoietin 2, Notch1 and D114 downregulation under hypoxic condition in tissues with gastrointestinal vascular malformation and human umbilical vein endothelial cells. J Dig Dis 15: 85-95, 2014.

35. Li Y, Fu S, Chen H, Feng Q, Gao Y, Xue H, Ge Z, Fang J and Xiao S: Inhibition of endothelial Slit2/Robo1 signaling by thalidomide restrains angiogenesis by blocking the PI3K/Akt pathway. Dig Dis Sci 59: 2958-2966, 2014.

36. Segers J, Di Fazio V, Ansiaux R, Martinive P, Feron O, Wallemacq P and Gallez B: Potentiation of cyclophosphamide chemotherapy using the anti-angiogenic drug thalidomide: importance of optimal scheduling to exploit the 'normalization' window of the tumor vasculature. Cancer Lett 244: 129-135, 2006.

37. Lebrin F, Srun S, Raymond K, Martin S, van den Brink S, Freitas C, Bréant C, Mathivet T, Larrivée B, Thomas JL, et al: Thalidomide stimulates vessel maturation and reduces epistaxis in individuals with hereditary hemorrhagic telangiectasia. Nat Med 16: 420-428, 2010

38. Goel S, Duda DG, Xu L, Munn LL, Boucher Y, Fukumura D and Jain RK: Normalization of the vasculature for treatment of cancer and other diseases. Physiol Rev 91: 1071-1121, 2011.

39. Floros T and Tarhini AA: Anticancer cytokines: biology and clinical effects of Interferon- $\alpha 2$, Interleukin (IL)-2, IL-15, IL-21, and IL-12. Semin Oncol 42: 539-548, 2015.

40. Mitsiades N, Mitsiades CS, Poulaki V, Chauhan D, Richardson PG Hideshima T, Munshi NC, Treon SP and Anderson KC: Apoptotic signaling induced by immunomodulatory thalidomide analogs in human multiple myeloma cells: therapeutic implications. Blood 99: 4525-4530, 2002.

41. Marriott JB, Clarke IA, Czajka A, Dredge K, Childs K, Man HW, Schafer P, Govinda S, Muller GW, Stirling DI and Dalgleish AG: A novel subclass of thalidomide analogue with anti-solid tumor activity in which caspase-dependent apoptosis is associated with altered expression of bcl-2 family proteins. Cancer Res 63 : 593-599, 2003

42. Schuster SR, Kortuem KM, Zhu YX, Braggio E, Shi CX, Bruins LA, Schmidt JE, Ahmann G, Kumar S, Rajkumar SV, et al: The clinical significance of cereblon expression in multiple myeloma. Leuk Res 38: 23-28, 2014.

43. Chung AS, Lee J and Ferrara N: Targeting the tumour vasculature: insights from physiological angiogenesis. Nat Rev Cancer 10: 505-514, 2010.

44. Sitkovsky MV, Kjaergaard J, Lukashev D and Ohta A: Hypoxia-adenosinergic immunosuppression: tumor protection by $\mathrm{T}$ regulatory cells and cancerous tissue hypoxia. Clin Cancer Res 14: 5947-5952, 2008
45. Palazon A, Aragones J, Morales-Kastresana A, de Landazuri MO and Melero I: Molecular pathways: hypoxia response in immune cells fighting or promoting cancer. Clin Cancer Res 18: $1207-1213,2012$

46. Huang Y, Goel S, Duda DG, Fukumura D and Jain RK: Vascular normalization as an emerging strategy to enhance cancer immunotherapy. Cancer Res 73: 2943-2948, 2013.

47. Hamzah J, Jugold M, Kiessling F, Rigby P, Manzur M, Marti HH, Rabie T, Kaden S, Gröne HJ, Hämmerling GJ, et al: Vascular normalization in Rgs5-deficient tumours promotes immune destruction. Nature 453: 410-414, 2008.

48. Rolny C, Mazzone M, Tugues S, Laoui D, Johansson I, Coulon C, Squadrito ML, Segura I, Li X, Knevels E, et al: HRG inhibits tumor growth and metastasis by inducing macrophage polarization and vessel normalization through downregulation of PlGF. Cancer Cell 19: 31-44, 2011.

49. Curiel TJ, Coukos G, Zou L, Alvarez X, Cheng P, Mottram P, Evdemon-Hogan M, Conejo-Garcia JR, Zhang L, Burow M, et al: Specific recruitment of regulatory $\mathrm{T}$ cells in ovarian carcinoma fosters immune privilege and predicts reduced survival. Nat Med 10: 942-949, 2004.

50. Galon J, Costes A, Sanchez-Cabo F, Kirilovsky A, Mlecnik B, Lagorce-Pagès C, Tosolini M, Camus M, Berger A, Wind P, et al: Type, density, and location of immune cells within human colorectal tumors predict clinical outcome. Science 313 : 1960-1964, 2006.

51. Tan TT and Coussens LM: Humoral immunity, inflammation and cancer. Curr Opin Immunol 19: 209-216, 2007.

52. Galustian C, Meyer B, Labarthe MC, Dredge K, Klaschka D, Henry J, Todryk S, Chen R, Muller G, Stirling D, et al: The anti-cancer agents lenalidomide and pomalidomide inhibit the proliferation and function of T regulatory cells. Cancer Immunol Immunother 58: 1033-1045, 2009.

53. Hanahan D and Weinberg RA: Hallmarks of cancer: the next generation. Cell 144: 646-674, 2011

54. de Visser KE and Coussens LM: The inflammatory tumor microenvironment and its impact on cancer development. Contrib Microbiol 13: 118-137, 2006.

55. Lin EY, Li JF, Gnatovskiy L, Deng Y, Zhu L, Grzesik DA, Qian H, Xue XN and Pollard JW: Macrophages regulate the angiogenic switch in a mouse model of breast cancer. Cancer Res 66: 11238-11246, 2006.

56. Murdoch C, Giannoudis A and Lewis CE: Mechanisms regulating the recruitment of macrophages into hypoxic areas of tumors and other ischemic tissues. Blood 104: 2224-2234, 2004.

57. Murdoch C, Muthana M, Coffelt SB and Lewis CE: The role of myeloid cells in the promotion of tumour angiogenesis. Nat Rev Cancer 8: 618-631, 2008.

58. Burke B, Tang N, Corke KP, Tazzyman D, Ameri K, Wells M and Lewis CE: Expression of HIF-1alpha by human macrophages: implications for the use of macrophages in hypoxia-regulated cancer gene therapy. J Pathol 196: 204-212, 2002.

59. Lewis CE and Pollard JW: Distinct role of macrophages in different tumor microenvironments. Cancer Res 66: 605-612, 2006.

60. Murdoch $\mathrm{C}$ and Lewis CE: Macrophage migration and gene expression in response to tumor hypoxia. Int J Cancer 117: 701-708, 2005.

61. Lee HS, Kwon HS, Park DE, Woo YD, Kim HY, Kim HR, Cho SH, Min KU, Kang HR and Chang YS: Thalidomide inhibits alternative activation of macrophages in vivo and in vitro: a potential mechanism of anti-asthmatic effect of thalidomide. PLoS One 10: e0123094, 2015.

62. Bruno A, Focaccetti C, Pagani A, Imperatori AS, Spagnoletti M, Rotolo N, Cantelmo AR, Franzi F, Capella C, Ferlazzo G, et al: The proangiogenic phenotype of natural killer cells in patients with non-small cell lung cancer. Neoplasia 15: 133-142, 2013.

63. Haslett PA, Corral LG, Albert M and Kaplan G: Thalidomide costimulates primary human $\mathrm{T}$ lymphocytes, preferentially inducing proliferation, cytokine production, and cytotoxic responses in the CD8+ subset. J Exp Med 187: 1885-1892, 1998.

64. Pober JS, Gimbrone MA Jr, Cotran RS, Reiss CS, Burakoff SJ, Fiers W and Ault KA: Ia expression by vascular endothelium is inducible by activated $\mathrm{T}$ cells and by human gamma interferon. J Exp Med 157: 1339-1353, 1983.

65. Pober JS, Gimbrone MA Jr, Lapierre LA, Mendrick DL, Fiers W, Rothlein R, Springer TA: Overlapping patterns of activation of human endothelial cells by interleukin 1, tumor necrosis factor, and immune interferon. J Immunol 137: 1893-1896, 1986. 
66. Choi J, Enis DR, Koh KP, Shiao SL and Pober JS: $\mathrm{T}$ lymphocyte-endothelial cell interactions. Annu Rev Immunol 22: 683-709, 2004

67. Trédan O, Lacroix-Triki M, Guiu S, Mouret-Reynier MA Barrière J, Bidard FC, Braccini AL, Mir O, Villanueva $\mathrm{C}$ and Barthélémy P: Angiogenesis and tumor microenvironment: bevacizumab in the breast cancer model. Target Oncol 10 189-198, 2015.

68. Rivas-Fuentes S, Salgado-Aguayo A, Pertuz Belloso S, Gorocica Rosete P, Alvarado-Vásquez N and Aquino-Jarquin G: Role of chemokines in non-small cell lung cancer: angiogenesis and inflammation. J Cancer 6: 938-952, 2015.

69. Dirkx AE, Oude Egbrink MG, Wagstaff J and Griffioen AW: Monocyte/macrophage infiltration in tumors: modulators of angiogenesis. J Leukoc Biol 80: 1183-1196, 2006.
70. FischerC,Jonckx B,Mazzone M,ZacchignaS,Loges S,Pattarini L, Chorianopoulos E, Liesenborghs L, Koch M, De Mol M, et al: Anti-PlGF inhibits growth of VEGF(R)-inhibitor-resistant tumors without affecting healthy vessels. Cell 131: 463-475, 2007.

71. Nakayama T, Yao L and Tosato G: Mast cell-derived angiopoietin-1 plays a critical role in the growth of plasma cell tumors. J Clin Invest 114: 1317-1325, 2004

72. Stockmann C, Schadendorf D, Klose R and Helfrich I: The impact of the immune system on tumor: angiogenesis and vascular remodeling. Front Oncol 4: 69, 2014.

73. Jain RK: Antiangiogenesis strategies revisited: from starving tumors to alleviating hypoxia. Cancer Cell 26: 605-622, 2014. 